\title{
Disability-adjusted Life Years for Diabetes in Cuban Children and Adolescents, 1990- 2010
}

\author{
Emma Domínguez-Alonso MD
}

\begin{abstract}
INTRODUCTION Shifts in diabetes onset to earlier ages, globally and in Cuba, signify greater risk of early complications and premature death, with consequent economic and social repercussions for families and health systems.
\end{abstract}

OBJECTIVE Describe the trend in diabetes burden in Cuban children and adolescents in the period 1990 to 2010, in terms of disabilityadjusted life years.

METHODS A descriptive epidemiological study was conducted of diabetes burden in Cuba, analyzing the years 1990, 1995, 2000, 2005 and 2010 for the age group 0-19 years. Disability-adjusted life years were obtained from the sum of potential years of life lost plus years lived with disability. The first is calculated based on total deaths in the country in which diabetes was recorded as underlying cause; the second from the product of severity, as assigned to diabetes in similar studies, and incidence and average duration, provided by the DISMOD II program, which estimates six internally consistent epidemiological indicators.

RESULTS Mortality indicators improved, with a decrease in the rate of potential years of life lost in boys from 21.9/100,000 population in 1990 to 0 in 2010, and in girls from $38.8 / 100,000$ in 1990 to $4.9 / 100,000$ in 2010 ( $1 \%$ of disability-adjusted life years in girls in 2010 , corresponding to one death). In contrast, years lived with disability increased by $134.5 \%$ in boys and $156.4 \%$ in girls. The net result was that disabilityadjusted life years increased by $>100 \%$ in both sexes (from 137.2 to $321.9 / 100,000$ in boys and from 157.3 to $403.3 / 100,000$ in girls, increases of $102.3 \%$ and $108.1 \%$, respectively).

CONCLUSIONS Disability-adjusted life years lost for diabetes in $\mathrm{Cu}$ ban children and adolescents have increased, due to disability, while mortality has decreased.

KEYWORDS Diabetes mellitus, childhood, adolescence, disability-adjusted life years, potential years of life lost, years lived with disability, Cuba

\section{INTRODUCTION}

The marked increase in the number of people with diabetes mellitus (DM) over the last few decades is due, in essence, to an aging population and to lifestyles associated with urbanization.[1,2] International Diabetes Federation 2014 estimates show a worldwide prevalence of $8.3 \%$ and predict a $53 \%$ increase by 2035. In 2014, DM caused 4.9 million deaths.[3]

Ninety percent of diabetes cases are type 2 (DM2),[4] influenced by complex interactions among factors such as genetic and epigenetic predisposition, environmental exposures and lifestyles.[2] Until recently, DM2 was considered exclusively a disease of adults, but in the past two decades, increasing numbers of cases have been seen in children and adolescents in numerous countries. $[5,6]$

Overweight (BMI $\geq 25$ and $<30$ ) and obesity (BMI $\geq 30$ ) are the best predictors of DM2.[7-9] Increased DM prevalence is directly associated with increased frequency of both.[2,4,8,9] Over $80 \%$ of children and adolescents with DM2 are overweight and some $40 \%$ are clinically obese.[10]

At the same time, incidence of type $1 \mathrm{DM}$, which chiefly appears at younger ages, has been increasing. Two international collaborations, DIAMOND[11] and EURODIAB,[12] have identified, although with geographical variations, a $3 \%$ annual increase in incidence, particularly due to cases in very young children. This increase is less clearly explained than that of DM2; several hypotheses have been developed, none conclusive.[4,13,14]

Needs for treatment, systematic blood glucose monitoring and diet impose a considerable economic burden on families and health systems. Furthermore, coping with a disease that in- volves lifelong behavioral changes is more difficult in children, who are still emotionally and intellectually immature, negatively influencing adherence to treatment.[3,15] Early onset of diabetes increases risk of complications in adulthood and consequently, premature death.[16,17] An additional challenge lies in the fact that a greater number of women are entering their childbearing years with diabetes, which has a negative impact on pregnancy outcomes.[18]

Systematic estimates of the global, regional and national burden of diabetes[1,2,11,12,19] tend to use measures of incidence, prevalence and mortality. However, isolated analysis of any of these is complex and of little help in setting priorities and allocating resources.

The 1990 Global Burden of Disease Study (GBD) provided estimates of the burden of 107 diseases or injuries and 10 risk factors for 8 geographic regions around the world, to inform health priorities, policymaking and resource allocation by governmental and nongovernmental agencies.[20] An indicator introduced in GBD 1990, disability-adjusted life years (DALY), has since been used by many research studies to report disease burden for a wide range of diseases,[21-24] including DM.[25-29]

DALY, an indicator rarely used in Cuba, integrates years of life lost due to premature death (termed potential years of life lost, or PYLL), and years of life "lost" by virtue of living with suboptimal quality of life (years lived with disability, or YLD).[20] Between 1990 and 2010, DM's all-age DALY rate increased by $30 \%$ worldwide.[24]

In Cuba, DM prevalence in the general population increased from $23.6 / 1000$ population in 2000 [30] to 55.7/1000 in 2014[31] 
with an increase in younger ages also, greater beginning in the group aged 10-14 years, in which the rate increased from 0.7 to $1.5 / 1000$ from 2000 to 2014 . DM prevalence in the group aged $15-24$ years was $3.8 / 1000$ in 2000 , and 5.4 and $13.8 / 1000$ in the groups aged 15-18 and 19-24 years, respectively, in 2014. $[30,31]$ Cuba's morbidity and mortality statistics do not distinguish between types of diabetes, thus it is not possible to attribute this rise to one type in particular.

DM has remained among the top ten causes of death in recent decades, with an increase in the age-standardized rate from 10.4 to $11.2 / 100,000$ from 2000 to 2014 .[30,31]

A literature review identified only two Cuban studies, conducted by the author of this paper, which quantified diabetes burden in terms of DALYs. The first included all ages and both sexes, for the period 1990-2005;[32] and the second, women of childbearing age, for the period 1990-2010.[33] Both showed an increase in DALY as a consequence of diabetes, primarily due to the disability component.

Given the particular complexity of diabetes at young ages and its epidemiological situation globally and nationally, its magnitude in the Cuban population needs to be determined using different methodologies, which will contribute more and better information to orient health policies. The objective of this paper is to describe the trend in diabetes burden in the Cuban population aged $<20$ years, from 1990 to 2010 , in terms of disabilityadjusted life years.

\section{METHODS}

A national, retrospective descriptive epidemiological study was done of DM burden in the population aged $<20$ years. The years analyzed were 1990, 1995, 2000, 2005 and 2010. Every fifth year was considered sufficient to demonstrate changes in DM burden trend over two decades.

Mortality burden estimate Calculations were based on total deaths in Cuba for ages 0-19 years in which diabetes was recorded as underlying cause of death. The Ministry of Public Health's National Statistics Division (DNE-MINSAP) provided data from its mortality database.

PYLL rates per 100,000 population were calculated, using the usual method adapted by $\mathrm{WHO}[20]$ and considering as maximum lifespan the estimated life expectancy for the periods corresponding to each of the years included. The following International Classification of Diseases codes were considered:

- For 1990, 1995 and 2000; ICD-9 codes 250.0-250.9

- For 2005 and 2010; ICD-10 codes E10-E14

Estimated life expectancy by five-year age group was obtained from Cuba's National Statistics Bureau.

Disability burden estimate The DISMOD II[34] program was used to obtain incidence and average duration, by inputting mortality, prevalence and remission data. Mortality and prevalence data were obtained from mortality databases and DNE-MINSAP primary care registries for continuous assessment and risk evaluation (CARE), respectively. Because
DM is a virtually incurable disease, we assigned a value of zero to remission. YLD were obtained from the product of diabetes incidence, average duration (obtained from DISMOD II output) and severity.

DISMOD II is open-source software used to estimate six internally consistent epidemiological indicators, requiring a minimum of at least three input variables from registries. It estimates the following epidemiological indicators: incidence, prevalence, mortality, remission, average age at onset and average duration.[34] The program was developed as part of the 1990 GBD,[20] to provide more reliable estimates (than from national and regional registries) to calculate disability burden.

Severity values To compute YLD associated with diabetes and its complications (diabetic retinopathy, diabetic nephropathy, diabetic neuropathy, diabetic foot, amputation, ischemic heart disease and cerebrovascular disease) as a whole (to encompass diabetes itself-i.e., without complications-and all of its complications) it was necessary to obtain an average severity, based on the severity of uncomplicated diabetes and the severities of each of the different complications considered. Weighting was based on prevalence of each condition. Sources for obtaining prevalence and severity values, as well as the methodology for obtaining weighted severity are described in a previous article, from which we took the resulting severity value (0.17).[35] Rates for YLD per 100,000 population were calculated.

Overall burden estimate DALY are the sum of PYLL and YLD. DALY rates (per 100,000 population) were calculated, as were the proportions of DALY corresponding to disability and to premature death.

To describe the trend, the percent relative change from the first to the last year in the series was calculated for each of three indicators.

Ethics All study data were retrieved from registries, with data management procedures ensuring individual confidentiality. The study was approved by the National Endocrinology Institute's Ethics Committee.

\section{RESULTS}

From 1990 to 2010, PYLL due to diabetes declined in Cuban children and adolescents of both sexes. There were zero PYLL in both sexes in 2005, and in boys in 2010. The overall PYLL rate dropped $92 \%$. Rates were higher in girls, although the rate of $4.9 / 100,000$ in 2010 corresponded to a single death (Table 1).

Table 2 shows losses of healthy life from disability. The YLD rate increased during the period, more than doubling the 1990 rates in 2010 in both sexes (increases of $134.6 \%$ in boys and $156.4 \%$ in girls), with the most notable increase from 2005 to 2010 . The overall rate increased $145.9 \%$.

DALY rates, in Table 3, show the same trend as for YLD, with an overall increase in 2010 of $105.4 \%$, greater in girls $(108.1 \%$, vs. $102.3 \%$ in boys). 
Figure 1 displays the contribution of each component (PYLL and YLD) to DALY by sex, showing a decrease in the contribution of premature death with a corresponding increase in that of disability. In 2005 and 2010, 100\% of DALY originated from disability in boys, and $100 \%$ and $99 \%$ in girls. The proportion of DALY due to premature death was greater in girls in four of the five years studied.

Table 1: Diabetes-related PYLL in Cuban children and adolescents, 1990-2010

\begin{tabular}{|c|c|c|c|}
\hline Year & M & $\mathbf{F}$ & Total \\
\hline \multicolumn{4}{|l|}{1990} \\
\hline Deaths & 5 & 7 & 12 \\
\hline PYLL (n) & 392.8 & 665.6 & 1058.4 \\
\hline PYLL (rate ${ }^{a}$ ) & 21.9 & 38.8 & 30.1 \\
\hline \multicolumn{4}{|l|}{1995} \\
\hline Deaths & 2 & 4 & 6 \\
\hline PYLL (n) & 126.2 & 408.1 & 534.4 \\
\hline PYLL (rate ${ }^{a}$ ) & 7.7 & 26.1 & 16.6 \\
\hline \multicolumn{4}{|l|}{2000} \\
\hline Deaths & 1 & 2 & 3 \\
\hline PYLL (n) & 58.2 & 200.4 & 258.6 \\
\hline PYLL (rate ${ }^{a}$ ) & 3.6 & 13.1 & 8.2 \\
\hline \multicolumn{4}{|l|}{2005} \\
\hline Deaths & 0 & 0 & 0 \\
\hline PYLL (n) & 0.0 & 0.0 & 0.0 \\
\hline PYLL (rate ${ }^{a}$ ) & 0.0 & 0.0 & 0.0 \\
\hline \multicolumn{4}{|l|}{2010} \\
\hline Deaths & 0 & 1 & 1 \\
\hline PYLL (n) & 0.0 & 63.7 & 63.7 \\
\hline PYLL (rate ${ }^{a}$ ) & 0.0 & 4.9 & 2.4 \\
\hline
\end{tabular}

aper100,000

PYLL: potential years of life lost

Table 2: Diabetes-related YLD in Cuban children and adolescents, 1990-2010

\begin{tabular}{|c|c|c|c|}
\hline Year & M & F & Total \\
\hline \multicolumn{4}{|l|}{1990} \\
\hline Incidence (n cases) & 300 & 306 & 606 \\
\hline YLD $\left(n^{a}\right)$ & 2465.1 & 2700.8 & 5165.9 \\
\hline YLD (rate ra,b $^{a}$ & 137.2 & 157.3 & 147.0 \\
\hline \multicolumn{4}{|l|}{1995} \\
\hline Incidence ( $\mathrm{n}$ cases) & 239 & 201 & 440 \\
\hline YLD $\left(n^{a}\right)$ & 1950.7 & 1718.6 & 3669.3 \\
\hline YLD (rate ra,b $^{a}$ & 118.2 & 109.8 & 114.2 \\
\hline \multicolumn{4}{|l|}{2000} \\
\hline Incidence (n cases) & 200 & 231 & 431 \\
\hline YLD $\left(n^{a}\right)$ & 1900.1 & 2309.1 & 4209.2 \\
\hline YLD (rate $\left.{ }^{a, b}\right)$ & 117.5 & 150.7 & 133.6 \\
\hline \multicolumn{4}{|l|}{2005} \\
\hline Incidence ( $\mathrm{n}$ cases) & 215 & 266 & 481 \\
\hline YLD $\left(n^{a}\right)$ & 2076.8 & 2590.4 & 4667.2 \\
\hline YLD (rate ra,b $^{a}$ & 135.5 & 178.9 & 156.5 \\
\hline \multicolumn{4}{|l|}{2010} \\
\hline Incidence ( $\mathrm{n}$ cases) & 462 & 511 & 973 \\
\hline YLD $\left(n^{a}\right)$ & 4469.9 & 5289.6 & 9759.5 \\
\hline YLD $\left(\right.$ rate $\left.^{a, b}\right)$ & 321.9 & 403.3 & 361.4 \\
\hline
\end{tabular}

Table 3: Diabetes-related DALY in Cuban children and adolescents, 1990-2010*

\begin{tabular}{|l|r|r|r|}
\hline Year & M & \multicolumn{1}{c|}{ F } & \multicolumn{1}{c|}{ Total } \\
\hline 1990 & 159.1 & 196.1 & 177.1 \\
\hline 1995 & 125.9 & 135.9 & 130.8 \\
\hline 2000 & 121.1 & 163.7 & 141.8 \\
\hline 2005 & 135.5 & 178.9 & 156.5 \\
\hline 2010 & 321.9 & 408.1 & 363.8 \\
\hline
\end{tabular}

*per 100,000

DALY: disability-adjusted life years

Figure 1: Contribution of disability and premature mortality to Diabetes-related DALY in Cuban children and adolescents, by sex, 1990-2010

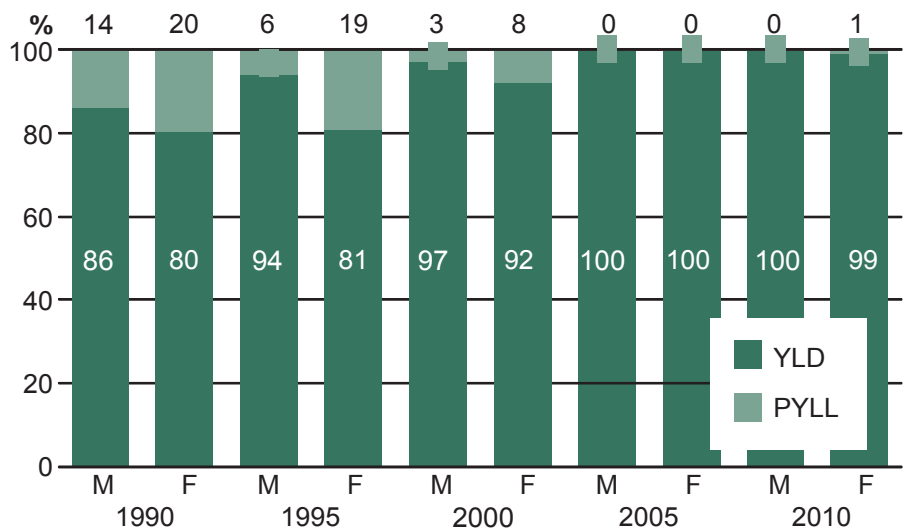

DALY: disability-adjusted life years

PYLL: potential years of life lost

YLD: years lived with disability

\section{DISCUSSION}

The decrease in PYLL due to diabetes from 1990 to 2010 in the study population is consistent with results of a previous study that described the trend in age of death from diabetes in Cuba in the same period. The study brought to light a shift in deaths to older ages, with average ages of death from DM in 2010 of 70.2 years in men and 72.2 years in women. Some $16.2 \%$ of deaths occurred in the group aged $\geq 85$ years, compared to only $9.9 \%$ in 1990.[19] A more recent study reported a decrease in PYLL due to DM in Cuban women of childbearing age in the same period.[33]

The two previous studies and results of this study coincide in showing a favorable trend in diabetes mortality in Cuba, with regard to age of death: fewer deaths are occurring in children, adolescents and women of childbearing age,[33] and a greater proportion at advanced ages.[19]

Worldwide, DM rose from 27th to 19th place as a cause of premature death from 1990 to 2010, with a 70\% increase in PYLL in those 20 years, [36] and the International Diabetes Federation reported that $50 \%$ of diabetes deaths in the world in 2014 occurred in people aged $<60$ years.[3]

According to estimates from the 2013 GBD, the contribution of DM to all deaths in the population aged $<5$ years in Cuba is $0.026 \%$. In the world, it is $0.071 \%$; in the USA, $0.14 \%$; in Mexico, $0.24 \%$; in Brazil, $0.17 \%$; and in Spain, $0.20 \%$. The specific values for the group aged $5-14$ years are $0.22 \%$ in Cuba and $0.25 \%$, $0.52 \%, 0.71 \%, 0.71 \%$ and $0.38 \%$, in the world, the USA, Mexico, Brazil and Spain, respectively. Likewise, the mortality rate in Cuba is lower for both age groups (0.029 and 0.042/100,000, 
respectively) compared with the US $(0.19$ and $0.069 / 100,000)$, Brazil $(0.6$ and $0.21 / 100,000)$ and Mexico $(0.81$ and $0.2 / 100,000)$. Spain also has higher DM mortality than Cuba in the group aged $<5$ years $(0.14 / 100,000)$, but lower in the group aged $5-14$ years $(0.038 / 100,000)$. It is not possible to make comparisons for the group aged 15-19 years since the 2013 GBD does not report independent values for this age group.[37]

With regard to the mortality trend from 1990 to 2013 , the 2013 GBD results are consistent with this study: annual decreases of $4.1 \%$ and $3.8 \%$ in age groups $<5$ and $5-14$ years, respectively. Actual global values were lower (2.73\% and $1.94 \%)$. The US and Mexico also had smaller decreases than Cuba, while Brazil's increased by $0.042 \%$ for the age group 5-14 years, and Spain decreased slightly more than Cuba $(4.6 \%$ and $3.9 \%$ for the two age groups, respectively).[37]

Cuba's health system guarantees universal and free health services.[38,39] In the case of DM, this principle is embodied in the National Diabetes Program, created in 1975, which has increased in priority since 1992. The basic aims of this program are to reduce DM morbidity and mortality, reduce frequency and severity of complications and improve quality of life for people living with DM, through medical care, prevention, education and research.[40] In line with Cuban health policies, the Program includes specific actions targeting particularly vulnerable population groups, including children and adolescents. These include care for all diabetic children and adolescents by endocrinologists at secondary and tertiary care levels, interacting with primary health care providers;[40] school involvement in patient management;[40] free or subsidized drugs (insulin and others) and blood sugar monitoring equipment (glucometers and test strips);[38,39] and comprehensive, multidisciplinary care emphasizing education. Along these lines, annual "Camps for Children and Adolescents with Diabetes Mellitus" have had a great impact; providing diabetes education since 1993, they are currently held in most Cuban provinces.[41]

This study's objectives and design do not permit an assertion that the favorable DM mortality trend in the population aged $<20$ years is a direct consequence of such policies and programs and the quality of their implementation, but it does support generating hypotheses to test in future studies. There is sufficient scientific evidence that proper management of diabetes using standardized protocols prevents complications and, consequently, premature death.[42]

The increased number of children and adolescents diagnosed with DM in recent decades in Cuba[30,31] and decreased diabetes mortality we observed in this population group have yielded an upward trend in YLD.

Unfortunately, Cuban morbidity and mortality statistics do not distinguish between diabetes types, which prevents linking increases in losses due to disability, and consequently in DALYs, reported in this paper, to a specific type. However, there is some evidence suggesting that DM2 has a predominant influence:

1. increased prevalence (most notable starting at age 10 years), $[30,31]$ which is consistent with patterns in other contexts,[37] and which is explained by physiological insulin resistance of puberty;

2. its association with the increase in excess weight at these ages; $[10,16]$ rising frequency of overweight and obesity in
Cuban children and adolescents, and greater presence of lifestyles conducive to its development (high-calorie diets and inadequate physical activity); $[43,44]$ and

3. its relationship to excessive maternal weight. $[2,3,44]$ The proportion of Cuban women who start pregnancy overweight or obese increased from $14.7 \%$ in 1997 to $27.1 \%$ in 2011.[43]

The increase in YLD and DALY rates could also, although to a lesser extent, be related to an increase in incidence of DM1, which rose-with some fluctuations-from 1.28/100,000 Cubans aged $<15$ years in 2000 to $2.18 / 100,000$ in 2008.[45]

The increase in DM-related DALY we observed is consistent with reports for the general population. A previous Cuban study that included both sexes and all age groups found that from 1990 to 2005, the DALY rate rose from 520 to $660 / 100,000$ in men and from 840 to $1120 / 100,000$ in women, mainly due to the disability component.[32] Similarly, in women of childbearing age, the DALY rate increased from 494 to $1375 / 100,000$ between 1990 and 2010 , with an increase in the contribution of disability and the corresponding drop in mortality.[33]

Worldwide, the all-age DM-related DALY rate increased from 523 to $680 / 100,000$ between 1990 and 2010. During the same period, DM rose from 29th to 14th place among all causes[24] and the DM-related YLD rate rose by $28.6 \%$, from 234 to $301 / 100,000$.[46] DM-related DALY show different patterns when comparing 2013 GBD estimates for the pediatric age group in Cuba and other countries. While the DALY rate for the group aged $<5$ years in Cuba was lower than that of the US, Mexico, Brazil and Spain, the DALY rate for the group aged 5-14 years was greater than the rate for these countries, except for Mexico, which had similar values. DM's contribution to total DALY in the Cuban population aged $5-14$ years $(1.2 \%)$ is greater than seen globally and in the four other countries compared.[37]

The 2013 GBD reported a $0.34 \%$ annual increase in the DMrelated DALY rate for Cuba between 1990 and 2013. There were decreases both globally and for the other four countries in the group aged $<5$ years, while DALY rates consistently rose in the group aged $5-14$ years, with values of $1.33 \%$ annually for Mexico and Cuba, $1.69 \%$ for Brazil, with slighter increases globally and for Spain and the US.[37]

All of the foregoing supports the need for reliable estimates of diabetes burden in different population groups, in order to guide and evaluate policies aimed at early diagnosis and effective treatment, and also, with high priority, at prevention.

This study has several limitations. First, prevalence data used to calculate years of healthy life lost to disability come from national registries, making it impossible to rule out a certain margin of error. Second, analysis of mortality based on deaths in which diabetes was recorded as the underlying cause of death means that deaths in which diabetes was a contributing or direct cause of death were not included. Finally, severity values are inevitably subjective, even more so because they were not obtained specifically for the Cuban context. It was necessary to take severity values from studies in other contexts because Cuba does not have its own severity estimates for diabetes and its complications. Obtaining Cuban values, not only for diabetes and its complications, but also 
for many other diseases, should be the subject of future studies, as an essential first step for carrying out national disease burden studies.

\section{CONCLUSIONS}

This is the first Cuban study to estimate diabetes burden (in terms of disability-adjusted life years) in the population aged $<20$ years. The particularities of diabetes in this population group give special meaning to its results. The frank downward trend in mortality reflects the comprehensiveness and quality of care for these patients. However, the increase in YLD, and consequently DALY, indicates the need to step up actions aimed at prevention, and to plan and allocate resources targeted to prevention and disease management in this population group. The results of this study are useful for design and implementation of programs and policies to continue to reduce DM burden in the pediatric population. $-1 /$ -

\section{REFERENCES}

1. Danaei G, Finucane M, Lu Y, Singh GM, Cowand MJ, Paciorek CJ, et al. National, regional, and global trends in fasting plasma glucose and diabetes prevalence since 1980: systematic analysis of health examination surveys and epidemiological studies with 370 country-years and 2.7 million participants. Lancet. $2011 \mathrm{Jul}$ 2;378(9785):31-40.

2. Chen L, Magliano DJ, Zimmet PZ. The worldwide epidemiology of type 2 diabetes mellitus-present and future perspectives. Nat Rev Endocrinol. 2012;8:228-36.

3. International Diabetes Federation. IDF Diabetes Atlas. 6th ed [Internet]. Brussels: International Diabetes Federation; 2014 [cited 2015 Sep 28]. Available from: www.idf.org/diabetesatlas

4. Kharroubi AT, Darwish HM. Diabetes mellitus: The epidemic of the century. World J Diabetes. 2015 Jun 25;6(6):850-67.

5. Fazeli Farsani $\mathrm{S}$, van der Aa MP, van der Vorst MM, Knibbe CA, de Boer A. Global trends in the incidence and prevalence of type 2 diabetes in children and adolescents: a systematic review and evaluation of methodological approaches. Diabetologia. 2013 Jul;56(7):1471-88.

6. Dabelea D, Mayer-Davis EJ, Saydah S, Imperatore G, Linder B, Divers J, et al. Prevalence of type 1 and type 2 diabetes among children and adolescents from 2001 to 2009. JAMA. 2014 May 7:311(17):1778-86.

7. Kodama S, Horikawa C, Fujihara K, Yoshizawa S, Yachi Y, Tanaka S, et al. Quantitative relationship between body weight gain in adulthood and incident type 2 diabetes: a meta-analysis. Obes Rev. 2014 Mar;15(3):202-14.

8. The NS, Richardson AS, Gordon-Larsen P. Timing and duration of obesity in relation to diabetes. Diabetes Care. 2013 Apr;36(4):865-72.

9. Johnson W, Soloway LE, Erickson D, Choh AC, Lee M, Chumlea WC, et al. A changing pattern of childhood BMI growth during the 20th century: $70 \mathrm{y}$ of data from the Fels Longitudinal Study. Am J Clin Nutr [Internet]. 2012 May [cited 2016 Jun 29];95(5):1136-43. Available from: http:// ajcn.nutrition.org/content/suppl/2012/04/30/ ajcn.111.022269.DC1.html

10. Reinehr T. Type 2 diabetes mellitus in children and adolescents. World J Diabetes. 2013 Dec 15;4(6):270-81.

11. DIAMOND Project Group. Incidence and trends of childhood Type 1 diabetes worldwide 19901999. Diabetes Med. 2006 Aug;23(8):857-66.

12. Patterson $C C$, Dahlquist $G G$, Gyürüs $E$, Green $A$ Soltész G; EURODIAB Study Group. Incidence trends for childhood type 1 diabetes in Europe during 1989-2003 and predicted new cases 2005-20: a multicenter prospective registration study. Lancet. 2009 Jun 13;373(9680):2027-33.

13. Dahlquist G. Can we slow the rising incidence of childhood onset autoimmune diabetes? The overload hypothesis. Diabetologia. 2006 Jan;49(1):20-4.

14. You WP, Henneberg M. Type 1 diabetes prevalence increasing globally and regionally: the role of natural selection and life expectancy at birth.
BMJ Open Diabetes Res Care. 2016 Mar 2 [cited 2016 Jun 29];4:e000161. Available from: http:// drc.bmj.com/content/4/1/e000161

15. Ledón-Llanes L. Impacto psicosocial de la diabetes mellitus, experiencias, significados y respuestas a la enfermedad. Rev Cubana Endocrinol [Internet]. 2012 Jan-Apr [cited 2016 Mar 23];23(1):76-97. Available from: http://scielo sld.cu/scielo.php?script=sci_arttext\&pid=\$1561 29532012000100007\&lng=es. Spanish.

16. D'Adamo E, Caprio S. Type 2 diabetes in youth: epidemiology and pathophysiology. Diabetes Care. 2011 May;34 Suppl 2:S161-5.

17. Pinhas-Hamiel O, Zeitler P. Acute and chronic complications of type 2 diabetes mellitus in children and adolescents. Lancet. 2007 May 26;369(9575):1823-31.

18. Singh $\mathrm{H}$, Murphy $\mathrm{HR}$, Hendrieckx $\mathrm{C}$, Ritterband $\mathrm{L}$, Speight J. The challenges and future considerations regarding pregnancy-related outcomes in women with pre-existing diabetes. Curr Diab Rep. 2013 Dec;13(6):869-76.

19. Domínguez-Alonso E. Edad de ocurrencia de los fallecimientos por diabetes en Cuba. Rev Cubana Endocrinol. 2013 Jan-Apr;24(1):3-17. Spanish.

20. Murray CJL, Lopez AD. The Global Burden of Disease: a comprehensive assessment of mortality and disability from diseases, injuries and risk factors in 1990 and projected to 2020. Cambridge: Harvard School of Public Health; 1996. p. 1-98.

21. Begg SJ, Vos T, Barker B, Stanley L, Lopez AD. The burden of disease and injury in Australia in the new millennium: measuring health loss from diseases, injuries and risk factors. Med J Aust. 2008 Jan 7;188(1):36-40.

22. Lai T, Habicht J, Kiivet RA. Measuring burden of disease in Estonia to support public health policy. Eur J Public Health. 2009 Oct; 19(5):541-7.

23. Lapostolle A, Lefranc A, Gremy I, Spira A. Sensitivity analysis in summary measure of population health in France. Eur J Public Health. 2008 Apr:18:195-200.

24. Murray CJL, Vos T, Lozano R, Naghavi M, Flaxman AD, Michaud C, et al. Disability-adjusted life years (DALYs) for 291 diseases and injuries in 21 regions, 1990-2010: a systematic analysis for the Global Burden of Disease Study 2010. Lancet. 2012 Dec 15;380(9859):2197-223.

25. Oliveira AF, Valente JG, Leite Ida C, Schramm JM, Azevedo AS, Gadelha AM. Global burden of disease attributable to diabetes mellitus in Brazil. Cad Saúde Publica. 2009 Jun;25(6):1234-44.

26. Khajedaluee M, Dadgarmoghaddam M, Saeedi R, Izadi-Mood Z, Abrishami M. The Burden of Diabetes in a developing country. Open J Preventive Med [Internet]. 2014 [cited 2016 Jun 29];4:175-81. Available from: http://file.scirp.org/ pdf/OJPM_2014041114001766.pdf

27. Escobedo J, Rodríguez-Abrego G, Aranda J, Zurita B, Ramírez T, Herrera J. Disabilityadjusted life-years (DALYs) for diabetes in Mexico in 2005: a cross-sectional burden of disease analysis. Lancet [Internet]. 2013 Jun
17 [cited 2016 Jun 29];381:S46. Available from: http://www.thelancet.com/journals/lancet/issue/ vol381nonull/PIIS0140-6736\%2813\%29X6030-1

28. Darbà J, Kaskens L, Detournay B, Kern W, Nicolucci A, Orozco-Beltrán D, et al. Disabilityadjusted life years lost due to diabetes in France, Italy, Germany, Spain, and the United Kingdom: a burden of illness study. Clinicoecon Outcomes Res [Internet]. 2015 Mar 23 [cited 2016 Jun 29];7:163-71. Available from: http://www.ncb .nlm.nih.gov/pmc/articles/PMC4376119/pdf/ ceor-7-163.pdf

29. Bhutani J, Bhutani S. Worldwide burden of diabetes. Indian J Endocrinol Metab. 2014 Nov;18(6):868-70.

30. National Health Statistics and Medical Records Division (CU). Anuario Estadístico de Salud 2000. Havana: Ministry of Public Health (CU) 2001. Spanish.

31. National Health Statistics and Medical Records Division (CU). Anuario Estadístico de Salud 2014. Havana: Ministry of Public Health (CU); 2015. 190 p. Spanish.

32. Domínguez-Alonso E, Seuc-Jo AH, Díaz-Díaz O, Aldana-Padilla D. La carga de la diabetes en Cuba, período 1990-2005. Rev Cubana Endocrinol [Internet]. 2008 May-Aug [cited 2012 Jul 20];19(2). Available from: http://scielo .sld.cu/scielo.php?script=sci_arttext\&pid $=$ S1561-29532008000200004. Spanish.

33. Domínguez E, Seuc AH. Años de vida saludable perdidos debido a la diabetes en mujeres $\mathrm{Cu}$ banas en edad fértil. Período 1990-2010. Rev ALAD. 2015;5:133-42. Spanish.

34. Barendregt JJ, Van Oortmarssen GJ, Vos T, Murray $\mathrm{CJ}$. A generic model for the assessment of disease epidemiology: The Computational $\mathrm{Ba}$ sis of Dis Mod II. Popul Health Metr. 2003 Apr $14 ; 1(1): 4$

35. Domínguez E, Seuc A, Aldana D, Licea M, Díaz O, López L. Impacto de la diabetes sobre la duración y calidad de vida de la población cubana: años 1990, 1995, 2000 y 2003. Rev Cubana Endocrinol [Internet]. 2006 May-Aug [cited 2013 Apr 19];17(2). Available from: http://scielo.sld .cu/scielo.php?script=sci_arttext\&pid=S1561 $-29532006000200003 \&$ lng=es\&nrm=iso. Spanish.

36. Lozano R, Naghavi M, Foreman K, Lim S, Shibuya K, Aboyans V, et al. Global and regional mortality from 235 causes of death for 20 age groups in 1990 and 2010: a systematic analysis for the Global Burden of Disease Study 2010 . Lancet. 2012 Dec 15;380(9859):2095-128.

37. GBD Compare [Internet]. Seattle: Institute for Health Metrics and Evaluation (IHME), University of Washington; c2015 [cited 2016 Sep 16]. Available from: http://vizhub.healthdata.org/gbd -compare

38. Pan American health Organization; World Health Organization. Oficina Regional para Las Américas. Salud en Las Américas. Cuba. Edición 2012 [Internet]. Washington, D.C.: Pan American Health Organization; 2012 [cited 2016 Sep 10] Available from: http://www.paho.org/salud-en -las-americas-2012/index.php?option=com_con 
tent $\&$ view $=$ article $\& i d=32 \% 3$ Acuba $\&$ catid $=21 \% 3$ Acountry-chapters\&ltemid=142\&lang=es. Spanish.

39. Domínguez Alonso E, Zacca E. Sistema de salud de Cuba. Parte X: Derecho a la salud en perspectiva latinoamericana, Vol 3. In: Clérico L, Ronconi L, Aldao M, editors. Tratado de Derecho a la Salud. Buenos Aires: Abeledo Perrot; 2013. Capítulo XCVIII. p. 2751-67. Spanish.

40. Díaz O. Programa Nacional de Diabetes [Internet]. Havana: Ministry of Public Health (CU); 2000 [cited 2016 Apr 13]. Available from: http:// www.sld.cu/galerias/pdf/sitios/diabetes/pro grama nacional de diabetes.pdf/. Spanish.

41. Vera-González $\bar{M}$, Âlvarez-Pérez MC, ArgoteParolis J, García-Sáez J, González-Padilla K, González-Calero TM, et al. Estándares para las Convivencias cubanas de niños y adolescentes con diabetes. Rev Cubana de Endocrinol. 2016;27(2):197-210. Spanish.
42. World Health Organization. Global Report on Diabetes [Internet]. Geneva: World Health Organization; 2016 [cited 2016 Jul 13]. Available from: http://apps.who.int/iris/bitstream/10665/204871 /1/9789241565257 eng.pdf

43. Jiménez-Acosta $\bar{S} M$, Rodríguez-Suárez $A$, Díaz-Sánchez ME. La obesidad en Cuba. Una mirada a su evolución en diferentes grupos poblacionales. Rev Cubana Aliment Nutr. 2013 Jul-Dec;23(2):297-308. Spanish.

44. Hernández-Triana M, Ruiz-Álvarez V. Obesidad, una epidemia mundial. Implicaciones de la genética. Rev Cubana Invest Bioméd [Internet]. 2007 [cited 2016 Jan 10];26(3). Available from: http:// scielo.sld.cu/scielo.php?pid=S0864 -030020 07000300010\&script=sci_arttext. Spanish.

45. Navarrete J. Registro de diabetes mellitus tipo 1 en edad pediátrica, su importancia. Experiencia Cubana. Proceedings of Congreso Internacional Controlando la Diabetes y a sus complicaciones más severas; 2014 Dec 8-12; Varadero, Cuba. Spanish.

46. Vos T, Flaxman AD, Naghavi M, Lozano R, Michaud C, Ezzati M, et al. Years lived with disability (YLDs) for 1160 sequelae of 289 diseases and injuries 1990-2010: a systematic analysis for the Global Burden of Disease Study 2010. Lancet. 2012 Dec 15;380(9859):2163-96

\section{THE AUTHOR}

Emma Domínguez-Alonso (emmada@ infomed.sld.cu), biostatistician. Associate researcher and professor, National Endocrinology Institute, Havana, Cuba

Submitted: May 20, 2016

Approved for publication: September 26, 2016

Disclosures: None

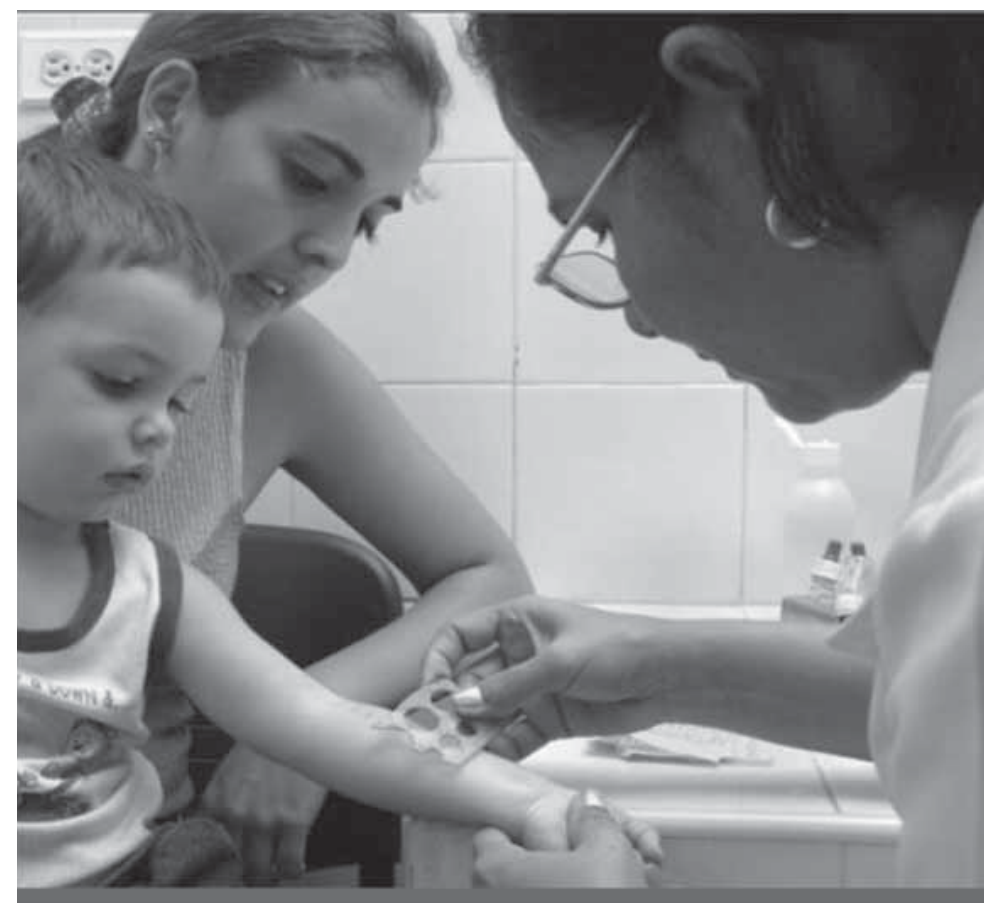

Organizer:

Cuban Society of Allergy, Asthma and Clinical Immunology

Information:

http://www.alergia2017.sld.cu/index.php/alergia/2017

\section{Allergy Cuba 2017 14th Central American and Caribbean Congress of Allergy and Clinical Immunology}

\section{5th Ibero-American Conference}

9th National Congress of Allergy

October 4-7, 2017

Havana Convention Center

\section{Main topics}

- Aeroallergens and air quality

- Epidemiology of allergic diseases

- Mechanisms of allergic inflammation

- Basic and clinical immunology

- Asthma epidemiology, diagnosis and treatment

- Rhinitis, sinusitis and allergic eye diseases

- Education and quality of life in allergic diseases 